\title{
Effect of Sprouting on the Anti-Nutritional Factors in Vigna radiate (L), Macrotyloma uniflorum (L), Vigna mungo $(\mathrm{L})$ And Cicer arietinum $(\mathrm{L})$
}

\author{
Divya D K, Ravi Varma B, Nagamani T S * \\ Department of PG Biotechnology, Government Science College (Autonomous), \\ Affiliated to Bangalore Central University, Banglore-560001
}

\begin{abstract}
The aim was to ascertain whether the process of sprouting reduced the concentration of antinutritional factors in Vigna radiata, Macrotyloma uniflorum, Vigna mungo (L) and Cicer arietinum (L) belonging to Fabaceae family. Nutrition is the most important concern in everyones diet plan and is also a need to have balanced food. Care must also be taken towards the anti-nutritional factors that inhibit the absorption of nutrients thereby decreasing the nutritional value of the food. The pulses were screened for major specific anti nutrients (tannins, phytic acid, alkaloids and cyanogenic glycosides) before and after sprouting. The process of sprouting decreased the concentration of tannins, phytic acids and cyanogenic glycosides whereas the alkaloid concentration was increased.
\end{abstract}

Keywords:- Alkaloids, Anti-Nutrients, Cyanogenic Glycoside, Nutrients, Phytic Acids, Sprouting, Tannins.

\section{INTRODUCTION}

Nutrients are the compounds which the body cannot produce and hence need to be supplemented. According to WHO these nutrients are to be supplemented from food and they play a vital role in disease prevention, growth and good health. Nutrients are majorly of two types namely, macro nutrients (carbohydrates, proteins and fat) and micro nutrients (vitamins and minerals). The nutrients are further broken down into smaller molecules in the body and then absorbed in the small intestine [6].

Anti-nutrients are the compounds that are present naturally in the plant sourced food which inhibit the absorption of nutrients. It is clearly not known how much of nutrient loss occurs due to their presence because it is based on the individual's metabolism. To lower the concentration of these anti-nutrients various types of processing techniques like milling, dehulling, soaking, germination, fermentation and cooking are followed [5].

All leguminous plants belong to family Fabaceae including more than sixteen thousand distinct species ranging in habitat from gaint trees to small annual herbs. The flowers of this plant have short hypanthium and a single carpel with a short gynopore and after fertilization produce fruits that are legumes.
Indian pulses are available in three types namely as whole pulse, split pulse with skin and split pulse without skin. Most of the foods in Indian cuisine make use of pulses, especially desserts are most commonly made with pulses. Often pulses are ground into flour to make a huge variety of food and even soaked and then ground into paste to make dishes and also many staple dishes are prepared from pulses by different cooking methods [3].

\section{MATERIALS AND METHODS}

\section{A. Sample collection and preparation}

The samples were brought from a well-known nearby vendor shop and was checked for any adulteration before buying. The samples were divided into two equal halves and the first half was put into the mixer to make them into fine powder. The other half was kept in a closed moistened condition at room temperature for sprouting. After the sprouting was complete the samples were spread on a paper and were dried under the shade until all the moisture content is lost. Then the sprouted samples were also made into fine powder.

\section{B. Determination of tannins}

The tannins were determined by the Van-Buren and Robinson method. To $500 \mathrm{mg}$ sample $50 \mathrm{ml}$ of distilled water was added and incubated on a mechanical shaker for one hour. The incubated samples were filtered into a $50 \mathrm{ml}$ volumetric flask and the volume was made up. $5 \mathrm{ml}$ of the filtrate was taken in a test tube to which $2 \mathrm{ml}$ of $0.1 \mathrm{M} \mathrm{FeCl} 3$ in $0.1 \mathrm{~N} \mathrm{HCl}$ (dilute to ten folds) and $1 \mathrm{ml}$ of $0.008 \mathrm{M}$ potassium ferro cyanide were added and the absorbance was read in a UV spectrophotometer at $605 \mathrm{~nm}$. Various concentrations of tannic acid were taken as the standard [4].

\section{Determination of phytic acid}

Phytic acid was determined using a modified method by (Omotoso, 2006, Wheeler \& Ferrel, 1971). To 5g of sample $50 \mathrm{ml}$ of $3 \%$ trichloroacetic acid was added on subjected to a shaking incubator for $30 \mathrm{~min}$ at $156 \mathrm{rpm}$. The sample mixtures were filtered and this suspension was centrifuged at $10000 \mathrm{rpm}$ for $15 \mathrm{~min}$. The supernatant was collected to which $2 \mathrm{ml}$ of $\mathrm{FeCl} 3(2 \mathrm{mg} / \mathrm{ml})$ solution was added and the samples were incubated for $45 \mathrm{~min}$ at 90 degree Celsius. The solution was again centrifuged (10000rpm for $15 \mathrm{~min}$ ) and the pellets were collected which were washed with $10 \mathrm{ml} 3 \%$ trichloroacetic acid solution. The mixture was incubated for $5 \mathrm{~min}$ at 90 degree Celsius and centrifuged (10000rpm for $15 \mathrm{~min}$ ). The pellets were 
resuspended in one $\mathrm{ml}$ distilled water and $1.5 \mathrm{ml}$ of $1.5 \mathrm{~N}$ $\mathrm{NaOH}$ and the volume was brought up to $15 \mathrm{ml}$ with distilled water. The mixture was subjected to heating in boiling water bath for $30 \mathrm{~min}$ and again centrifuged (10000rpm for 15min). Filter while hot and it was washed with $40 \mathrm{ml}$ hot distilled. The precipitate was collected to which $20 \mathrm{ml}$ of $3.2 \mathrm{~N}$ HNO3 was added the volume was made up to $50 \mathrm{ml}$. Of the $50 \mathrm{ml}$ sample $2.5 \mathrm{ml}$ was taken and it was made up to $35 \mathrm{ml}$ with distilled water to which $10 \mathrm{ml}$ of $1.5 \mathrm{M} \mathrm{KCN}$ was added and was calibrated to $50 \mathrm{ml}$ with distilled water. The samples were read at $480 \mathrm{~nm}$ in a UV spectrometer with in $1 \mathrm{~min}$ [4].

\section{Determination of alkaloids}

The presence of alkaloid was determined by precipitation method by (Harborne, 1973; Edeoga et al., 2005) with minor modifications. $2.5 \mathrm{~g}$ of the sample was mixed with $200 \mathrm{ml}$ of $10 \%$ acetic acid on ethanol and incubated fir 4 hours at room temperature. The extract was filtered and concentrated to $50 \mathrm{ml}$ on a rotary evaporator at $60 \mathrm{oC}$. To the concentrated extract $1 \mathrm{ml}$ of concentrated ammonium hydroxide was added drop wise until the precipitation was complete. The solution was allowed to stand for the precipitate to settle. The residue was collected and dried at room temperature. The dry weight of the residue was recorded in grams [4].

\section{E. Determination of cyanogenic glycosides}

The concentration of cyanogenic glycoside was determined by (Onwuka and Olopade, 2005) with slight modifications. To $25 \mathrm{ml}$ of distilled water $2.5 \mathrm{~g}$ of the sample was added and was allowed to stand for overnight. Incubated mixture was filtered, $1 \mathrm{ml}$ of the filtrate was taken in a test tube to which $4 \mathrm{ml}$ of alkaline picrate was added and incubated in a boiling water bath for 15 minutes. After the incubation the solutions were allowed to cool and the color change was read in the UV spectrophotometer at $490 \mathrm{~nm}$. Various concentrations of $\mathrm{KCN}$ solution were prepared for the standard curve. The concentration of cyanogenic glycoside were calculated using the equation cyanogenic glycosides $(\mathrm{mg} / 100 \mathrm{~g})=$ concentration $(\mathrm{mg}) * 10 /$ weight of the sample [4].

\section{RESULTS AND DISCUSSION}

The four samples chosen are mentioned as follows
S1: Vigna radiata
S2: Macrotyloma uniflorum
SS1: Sprouted sample 1
S3: Vigna mungo
SS2: Sprouted sample 2
S4: Cicer arietinum
SS3: Sprouted sample 3
SS4: Sprouted sample 4

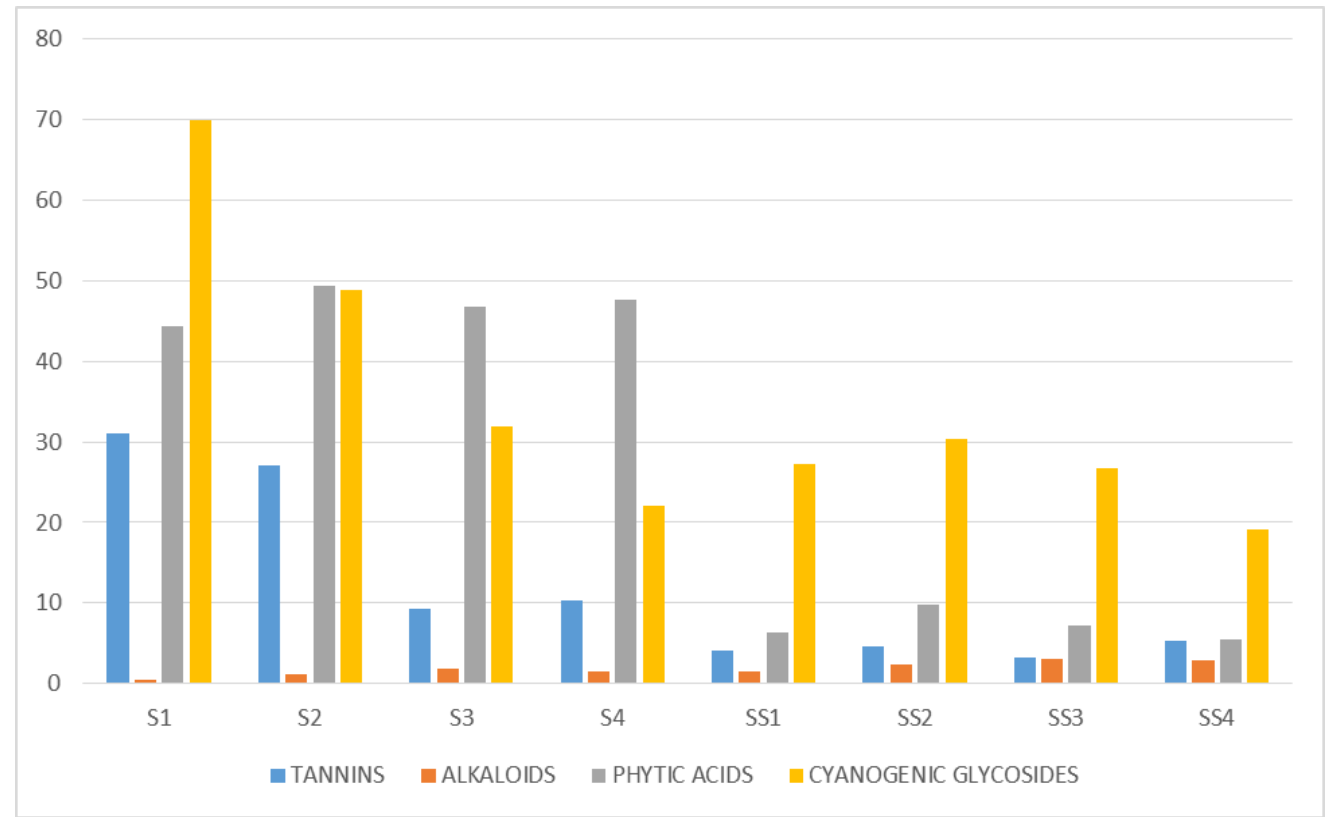

Fig 1

Tannins have found to affect protein digestibility by forming insoluble complexes and interfering with their bioavailability. Phytate being one of the major anti-nutrient reduces the bioavailability of metal ions like zinc and also affects the protein and starch digestion. Alkaloids are the compounds containing organic nitrogen which act as toxic substances in human liver. Cyanogens produce toxic products when hydrolyzed as they have the ability to link with $\mathrm{Fe} 2+, \mathrm{Mn} 2+$ and $\mathrm{Cu} 2+$ which are the functional groups of many enzymes [4]. In the present study the concentration of tannins, phytic acids and cyanogenic glycosides have been decreased in the sprouted samples when compared to the non-sprouted samples, thereby increasing the bioavailability and digestibility of nutrients. Whereas the concentration of the alkaloids have been increased, alkaloid being one of the anti-nutrient it also has 
several biological activity such as anti-inflammatory, anticancer, analgesics, anti-fungal, anti-microbial and so on. Hence increased concentration of alkaloid may show pharmacological activity thereby increasing the nutritional value of the food.

\section{CONCLUSION}

Indian cuisine involves different types of plant sourced food especially cereals and pulses which provides a need to know the importance and the effect of antinutrients. In the present study presence of anti-nutrients in the samples disclosed them to be a source of anti-nutrients, but during the process of sprouting a noteworthy impact was noted on reducing the concentrations of anti-nutrients such as tannins, phytic acids, alkaloids and cyanogenic glycosides thereby increasing the quality and nutritional value of the food. Thus making them a source of natural neutraceuticals, whereas further more studies are to be made on the cooked and germinated food both in vitro and in vivo.

\section{REFERENCES}

[1]. Aberounmand, A. and Deokule, S.S. (2010). Screening of some nutrients and anti-nutrients compounds in some plant foods of Iran and India. Journal of Agricultural Technology 6(4):777-781.

[2]. Aneta Popova and Dasha Mihaylova (2019). Antinutrients in Plant-based Foods: A Review. The Open Biotechnology Journal 1874-0707/19.

[3]. Embaby, H.E. (2010). Effect of soaking, dehulling, and cooking methods on certain antinutrients and in vitro protein digestibility of bitter and sweet lupin seeds. Food Science and Biotechnology. 19(4), 10551062

[4]. Humaria Essack, Bharti Odhav, John Jason Mellem. (2017). Screening of traditional South African leafy vegetables for specific anti-nutritional factors before and after processing. Food Science and Technology.

[5]. Leticia X. Lopez-Martinez, Nayely Leyva-Lopez, Erick P. Gutierrez-Grijialva, j. Basilio Heredia. (2017). Effect of cooking and germination on bioactive compounds in pulses and their health benefits. Journal of Functional Foods.

[6]. Shivaprasad Mahadkar, Sujata Valvi and Varsha Rathod (2012). Screening of anti-nutritional factors from some wild edible plants. Scholars research library, 2(2):251-255.

[7]. Seema Sharma, Dharmesh C. Saxena, Charanjit S. Riar (2015). Analysing the effect of germination on phenolic, dietary fibers, minerals and $\gamma$ - amino butyric acid contents of barnyard millet (Echinochloa firmentaceae). Food Biosciences 13 (2016) 60-68.

[8]. Nanna Roos, Jens Chirstian Sorensen, Hilmer Sorensen et.al (2013). Screening for anti-nutritional compounds in complementary foods and food aid products for infants and young children. Blackwell publishing Ltd Maternal and Child Nutrition, 9 (Suppl. 1). pp.47-71.
[9]. Velisek, J. (2014). The Chemistry of Food, Nova Jersey: Wiley-Blackwell.

[10]. Yadav, S.K., \& Sehgal, S. (2003). Effect of domestic processing and cooking on selected antinutrient contents of some green leafy vegetables. Plant Foods for Human Nutrition, 58(3), 1-11. 